\section{0,000 Years of Cosmic Dust in Antarctic Ice}

\author{
Gisela Winckler ${ }^{1 *}$ and Hubertus Fischer ${ }^{2}$
}

A bout 40,000 tons of extraterrestrial matter fall to Earth each year. A fraction of the cosmic dust is archived in the polar ice sheets [e.g., $(1,2)]$, side by side with the much more common terrestrial dust. In addition to its astrophysical importance, cosmic dust has the potential to constrain rates of sedimentation in various geological archives. However, the cosmic dust flux, especially its short- and long-term temporal variability, is poorly known. Here, we present a highresolution, glacial-to-interglacial record of cosmic dust flux from an Antarctic ice core.

We used ${ }^{3} \mathrm{He}$, the rare isotope of helium, to trace the fraction of cosmic dust that retains its gas load during atmospheric entry. The samples, from the EPICA (European Project for Ice Coring in Antarctica) ice core drilled in Dronning Maud Land, cover the time period from 6800 to 29,000 years before the present. We developed a technique to sample the excess water stream of a continuous chemical meltwater analysis, allowing us to process sufficiently large ice samples $(\sim 5 \mathrm{~kg})$. Particulate dust was collected on silver filters (2); helium isotopes were determined by mass spectrometry (3). Each sample covers between 300 and 600 years for the glacial and between 150 and 200 years for the interglacial.

The filtered particles contain a binary mixture of extraterrestrial and terrigeneous helium, bound in the cosmic and terrestrial dust, respectively. The helium isotopic ratios of these two end-members differ by four orders of magnitude $\left({ }^{4} \mathrm{He} /{ }^{3} \mathrm{He}_{\mathrm{ET}} \sim 4200\right.$ and ${ }^{4} \mathrm{He} /{ }^{3} \mathrm{He}_{\mathrm{TERR}} \sim 2.5 \times 10^{7}$ ), so identification of the extraterrestrial component is unambiguous.

The low ${ }^{4} \mathrm{He} /{ }^{3} \mathrm{He}$ ratios (Fig. 1A) measured in the bulk particulate matter are very close to that of the extraterrestrial end-member, indicating that nearly all the ${ }^{3} \mathrm{He}$ in the ice is of extraterrestrial origin. By using the reconstructed snow accumulation rates for the ice core, we derived the extraterrestrial ${ }^{3} \mathrm{He}$ flux (Fig. 1B). The ${ }^{3} \mathrm{He}$ flux is well defined at $7.5 \times 10^{-13} \pm 2.9 \times 10^{-13} \mathrm{~cm}^{3} \mathrm{STP}$ $\mathrm{cm}^{-2} \mathrm{ky}^{-1}$ (median \pm median of the absolute deviation from the median, where $\mathrm{cm}^{3}$ STP is cubic centimeter at standard temperature and pressure and ky is 1000 years) despite the scatter in the ${ }^{3} \mathrm{He}$ fluxes, which is caused by the small number of interplanetary dust particles (IDPs) in each sample. Most importantly, we do not observe any significant change in the ${ }^{3} \mathrm{He}$ flux from glacial $(>13 \mathrm{ky}: 7.5 \times$ $10^{-13} \pm 2.6 \times 10^{-13} \mathrm{~cm}^{3}$ STP $\left.\mathrm{cm}^{-2} \mathrm{ky}^{-1}\right)$ to Holocene $\left(<13\right.$ ky: $7.7 \times 10^{-13} \pm 3.3 \times 10^{-13}$ $\mathrm{cm}^{3}$ STP $\left.\mathrm{cm}^{-2} \mathrm{ky}^{-1}\right)$ conditions. This relatively constant ${ }^{3} \mathrm{He}$ flux rules out the input of interplanetary dust as a driver of the late Pleistocene 100-ky glacial cycles (4), as previously suggested (5).

Our high-resolution record is in agreement with previous estimates of the extraterrestrial ${ }^{3} \mathrm{He}$ flux derived from low-latitude marine sediment cores over the past $200 \mathrm{ky}$ (6) and from Holocene ice from Vostok (2), thus indicating a globally uniform deposition of ${ }^{3} \mathrm{He}$-bearing IDPs. This supports the use of ${ }^{3} \mathrm{He}$ as constant flux proxy in paleocli-
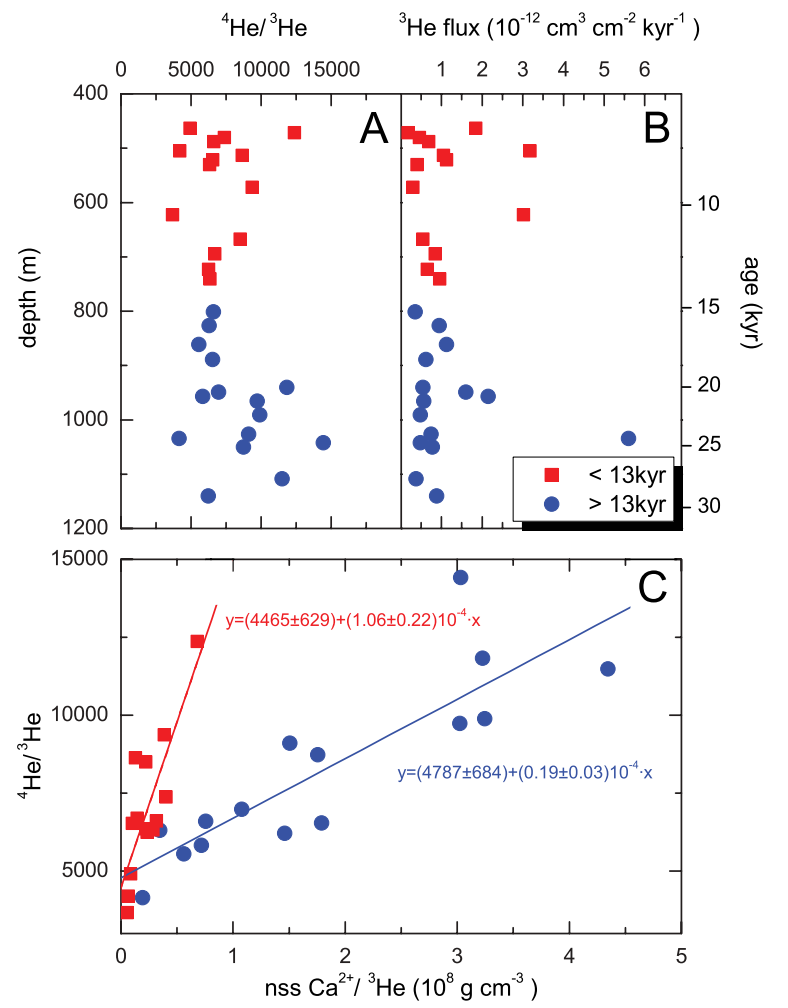

Fig. 1. Helium isotope characteristics of the ice samples from Dronning Maud Land (Antarctica). (A and B) The depth records of ${ }^{4} \mathrm{He} /{ }^{\beta} \mathrm{He}$ and the ${ }^{3} \mathrm{He}$ flux, respectively. Age scale is given on the right $y$ axis. (C) An isotope mixing diagram with nss $\mathrm{Ca}^{2+}$ as the terrestrial dust reference species. Glacial and interglacial ice samples fall along two well-defined mixing lines with matching $y$ intercepts $\left({ }^{4} \mathrm{He} / 3 \mathrm{He}\right.$ ratio of the extraterrestrial end-member) and distinct slopes, suggesting a glacialinterglacial change in terrestrial dust source distribution. mate studies, for example, to derive quantitative accumulation rate estimates in deep ice cores.

Our data permit an independent estimate of the helium isotope ratio of the interplanetary dust deposited on Earth. An isotope mixing diagram (Fig. 1C) shows well-defined mixing lines with distinct terrestrial end-members, but anchored in the same extraterrestrial end-member, for both glacial and interglacial samples. The intercept with the ${ }^{4} \mathrm{He} /{ }^{\beta} \mathrm{He}$ axis, representing purely IDP-derived helium, is $4626 \pm 465$, indistinguishable from the average ${ }^{4} \mathrm{He} /{ }^{\beta} \mathrm{He}$ ratio of about $4170 \pm 500$ observed in studies of individual stratospheric IDPs (7).

The mixing diagram also indicates a change in the distribution of terrestrial dust sources between glacial and interglacial samples. Glacial ice shows ${ }^{4} \mathrm{He} /$ non-sea salt $\mathrm{Ca}^{2+}$ (nss $\mathrm{Ca}^{2+}$ ) ratios that are much lower than those of the interglacial ice. This result is consistent with the moderate decrease of the terrigeneous ${ }^{4} \mathrm{He}$ flux from glacial to interglacial values by about a factor of 2 , which is much lower than the 10 - to 15 -fold decrease observed in particulate dust flux measurements (8). We suggest that different dust sources, exposed continental shelves, or freshly generated glaciogenic material may have influenced the glacial dust deposition on the Antarctic ice sheet.

Our excess water technique enables parallel high-resolution reconstruction of extraterrestrial and terrestrial dust fluxes from ice cores. Large volume sampling, together with noble gas mass spectrometry, has opened a prospect to use IDPs and ${ }^{3} \mathrm{He}$ fluxes to pace the deposit of material and chemical signals in settings where the flow of time is otherwise only poorly constrained.

\section{References and Notes}

1. P. Gabrielli et al., Nature 432, 1011 (2004).

2. E. J. Brook, M. D. Kurz, J. Curtice, S. Cowburn, Geophys. Res. Lett. 27, 3145 (2000).

3. Information on material and methods is available on Science Online.

4. G. Winckler, R. F. Anderson, M. Stute, P. Schlosser, Quat. Sci. Rev. 23, 1873 (2004).

5. R. A. Muller, G. J. MacDonald, Nature 377, 107 (1995).

6. F. Marcantonio et al., Paleoceanography 16, 260 (2001).

7. A. O. Nier, D. J. Schlutter, Meteoritics 27, 166 (1992).

8. EPICA community members, Nature 429, 623 (2004).

9. G.W. acknowledges support from the Comer Science and Education Foundation. We thank P. Schlosser, M. Stute, and R. F. Anderson for continued support of the lab. This work is a contribution to EPICA, a joint European Science Foundation/ European Commission scientific program funded by the European Union and by national contributions from Belgium, Denmark, France, Germany, Italy, Netherlands, Norway, Sweden, Switzerland, and the UK. This is L-DEO publication 6901 and EPICA publication 154.

Supporting Online Material

www.sciencemag.org/cgi/content/full/313/5786/491/DC1 Materials and Methods

15 March 2006; accepted 16 May 2006 10.1126/science. 1127469

${ }^{1}$ Lamont-Doherty Earth Observatory (L-DEO), Earth Institute at Columbia University, Palisades, NY 10964, USA. ${ }^{2}$ Alfred Wegener Institute for Polar and Marine Research, Columbusstrasse, 27568 Bremerhaven, Germany.

*To whom correspondence should be addressed. E-mail: winckler@ldeo.columbia.edu 